\title{
Use of Low Dos Aspirin in Women with Increased Risk of Preeclampsia
}

\author{
R Vaghela C. ${ }^{1 *}$, Nanjibhai Sarvaiya V. ${ }^{2}$ \\ DOI: https://doi.org/10.17511/joog.2020.i06.04 \\ 1* Chetna R Vaghela, Assistant Professor, Department of Obstetrics and Gynecology, Government Medical College, Bhavnagar, Gujarat, \\ India. \\ 2 Vipul Nanjibhai Sarvaiya, Assistant Professor, Department of Obstetrics and Gynecology, Government Medical College, Bhavnagar, \\ Gujarat, India.
}

Introduction: The role of aspirin in the primary or secondary prevention of preeclampsia has been the subject of numerous studies and great controversy. Our aim reports on LDA usage rates by women with an increased PE risk, as well as on determinants and reasons given for use and nonuse. Material and Method: In this multicenter, double-blind, placebo-controlled trial, the current study randomly assigned 2100 women with singleton pregnancies who were at high risk for preterm preeclampsia to receive aspirin, at a dose of $150 \mathrm{mg}$ per day, or placebo from 11 to 14 weeks of gestation until 36 weeks of gestation. The primary outcome was delivery with preeclampsia before 37 weeks of gestation. The analysis was performed according to the intention-to-treat principle. Results: Preterm preeclampsia occurred in 13 participants (1.6\%) in the aspirin group, as compared with $35(4.3 \%)$ in the placebo group (odds ratio in the aspirin group, $0.38 ; 95 \%$ confidence interval, 0.20 to $0.74 ; P=0.004)$. Results were materially unchanged in a sensitivity analysis that took into account participants who had withdrawn or were lost to follow-up. Conclusion: This randomized trial showed that among women with singleton pregnancies who were identified using first-trimester screening as being at high risk for preterm preeclampsia, the administration of aspirin at a dose of $150 \mathrm{mg}$ per day from 11 to 14 weeks of gestation until 36 weeks of gestation resulted in a significantly lower incidence of preterm preeclampsia than that with placebo.

Keywords: Low dose Aspirin, Preeclampsia, Pregnancy, Prevention

\section{Corresponding Author}

Chetna R Vaghela, Assistant Professor, Department of Obstetrics and Gynecology, Government Medical College, Bhavnagar, Gujarat, India. Email: chetnabv@gmail.com

\section{How to Cite this Article}

Vaghela CR, Sarvaiya VN. Use of Low Dos Aspirin in Women with Increased Risk of Preeclampsia. Obs Gyne Review J Obstet Gynecol. 2020;6(6):125-130. Available From

https://obstetrics.medresearch.in/index.php/joog/art icle/view/125
To Browse

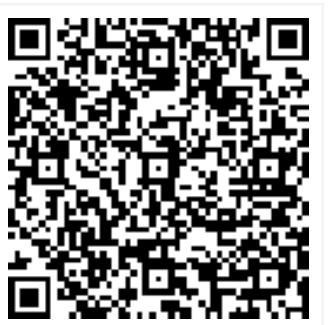

Manuscript Received 2020-11-27

Conflict of Interest No
Review Round 1 2020-12-07

Funding $\mathrm{Nil}$

Review Round 2
2020-12-17
$\begin{gathered}\text { Ethical Approval } \\ \text { Yes }\end{gathered}$

Review Round 2 Yes
Review Round 3

Plagiarism X-checker $6 \%$
Accepted 2020-12-29

(C) 2020 by Chetna R Vaghela, Vipul Nanjibhai Sarvaiya and Published by Siddharth Health Research and Social Welfare Society. This is an Open Áccess article licensed under a Creative Commons Attribution 4.0 International License https://creativecommons.org/licenses/by/4.0/ unported [CC BY 4.0]. 


\section{Introduction}

Antiplatelet agents are pivotal in both primary and secondary prevention of coronary artery disease and cerebrovascular disease worldwide. It has been postulated that a significant proportion of individuals exhibit a suboptimal response to aspirin, defined biochemically as diminished suppression of platelet activation or clinically as the development of thrombotic events while on treatment. Aspirin is currently the most widely prescribed treatment in the prevention of cardiovascular complications $[1,2]$.

At low doses, aspirin is also widely used to prevent pregnancy-related vascular disorders, such as preeclampsia and intrauterine growth restriction, and maternal disorders like antiphospholipid syndrome. The indications for the use of aspirin during pregnancy are, however, the subject of much controversy [3].

A breakthrough in the acceptance of the beneficial effect of aspirin was achieved by Bujold et al.'s meta-analysis which focussed on the onset of aspirin use and which demonstrated that early start, at least before 16 weeks of gestation, had a beneficial effect. Consequently, in 2010 the UK National Institute for Health and Care Excellence (NICE) recommended aspirin to women at risk of HDP 2010 [4].

Preeclampsia is a multisystem disorder of pregnancy that is usually defined as hypertension and proteinuria diagnosed after 20 weeks of gestation. Hypertension in pregnancy is defined as a systolic blood pressure of $140 \mathrm{mmHg}$ or more and a diastolic blood pressure of $90 \mathrm{mmHg}$ or more in two separate measurements at least 4-6 $\mathrm{h}$ apart. It affects about $2-8 \%$ of pregnancies and remains a major cause of maternal mortality and morbidity, preterm birth, perinatal death, and fetal growth restriction $[5,6]$.

In Europe, preeclampsia affects $1 \%$ of the general population, including $1.5 \%$ of nulliparas. Although its prevalence is low, preeclampsia causes substantial maternal and perinatal morbidity is the second cause of maternal mortality worldwide and is one of the five leading causes of maternal mortality in the developed world. Apart from delivery, there is no effective treatment for preeclampsia, making primary and secondary prevention of preeclampsia a major public health issue $[3,7]$.
For over 30 years, the role of aspirin in the primary or secondary prevention of preeclampsia has been the subject of numerous studies and great controversy. The indications for aspirin, its dosage, and gestational age at the start of aspirin treatment are still debated.8 Our aim reports on LDA usage rates by women with an increased PE risk, as well as on determinants and reasons given for use and non-use.

\section{Materials and Methods}

The present study was done in the department of gynecology associated with the medical college and hospital. A prediction tool was used to assess the women's preeclampsia risk during the first antenatal visit. The ethical clearance certificate was obtained from the ethical committee of the institute. The written consent was obtained from the women who participated in the study.

The present study is the double-blind trial; the comparison was done between the aspirin at a dose of $150 \mathrm{mg}$ per day with placebo that was administered from 11 to 14 weeks of gestation until 36 weeks of gestation in women with singleton pregnancies who were at high risk for preterm preeclampsia. All women $\geq 18$ years old with a singleton pregnancy were eligible for inclusion. Women were recruited from 2015 to 2016 at their first prenatal visit ( $<16$ weeks of pregnancy), at which time their healthcare professional used the prediction tool.

Exclusion criteria were the following: unconscious or severely ill status, learning difficulties or serious mental illness, major fetal abnormality identified at the time that scanning was performed at 11 to 13 weeks of gestation, regular treatment with aspirin within 28 days before screening, bleeding disorder such as von Willebrand's disease, peptic ulceration, hypersensitivity to aspirin, long-term use of nonsteroidal anti-inflammatory medication, and participation in another drug trial within 28 days before screening. Potential trial participants were given written information about the trial, and those who agreed to participate provided written informed consent.

Eligible women were randomly assigned, in a $1: 1$ ratio, with the use of a Web-based system (Sealed Envelope), to receive either aspirin or placebo, and in the random-sequence generation, there was stratification according to participating center. 
The aspirin and placebo tablets were manufactured by Actavis UK and were packaged, labeled, stored, and distributed by Mawdsley-Brooks. The placebo tablets were identical to the aspirin tablets concerning variables such as size, thickness, physical properties, and appearance. After randomization, the participants have prescribed the assigned trial product and received instructions to take one tablet every night throughout the trial and to stop taking tablets at 36 weeks of gestation or, in the event of early delivery, at the onset of labor.

The current study assessed adherence by counting the tablets that were returned by participants at each visit and by the participants' reporting of tablet counts during each telephone interview. The total number of tablets taken was calculated by subtracting the number of tablets returned from the number of tablets prescribed.

Adherence was considered to be good if the reported intake of tablets was $85 \%$ or more of the total number that participants were expected to have taken between the date of randomization and the date of the visit at 36 weeks of gestation or the date of delivery if delivery occurred before 36 weeks of gestation. Adherence was considered to be moderate if the intake was between $50 \%$ and $84.9 \%$ and considered to be poor if it was less than $50 \%$.

\section{Statistical analysis}

Statistical analyses were performed on an intentionto-treat basis, and no interim analyses were performed. Logistic-regression analysis was used to determine the significance of the between-group difference in the incidence of preterm preeclampsia. A Pvalue $<0.05$ will be considered statistically significant. Statistical analysis will be performed by a statistician using SPSS Statistics version software.

\section{Results}

The aim of the study reports on LDA and placebo usage rates by women with an increased PE risk. A total of 3000 women were found to be at high risk for preterm preeclampsia were included in the study. However, 300 of these women (10\%) were excluded from recruitment to the trial because they did not fulfill the eligibility criteria. Of the 2700 eligible women, 2100 agreed to participate in the trial. There were no significant differences between the aspirin group and the placebo group about the characteristics of the participants at baseline.
In the aspirin group, there were 22 miscarriages before 24 weeks of gestation, 4 pregnancy terminations for fetal abnormalities at or before 24 weeks of gestation, 2 pregnancy termination for severe fetal growth restriction and preeclampsia at 24 weeks of gestation, 14 stillbirths at or after 24 weeks of gestation, 2 neonatal death within 28 days after birth, and 1006 live births of infants who survived until discharge from the hospital. In the placebo group, there were 24 miscarriages before 24 weeks of gestation, 8 pregnancy terminations for fetal abnormalities at or before 24 weeks of gestation, no pregnancy terminations for severe fetal growth restriction and preeclampsia at 24 weeks of gestation, 24 stillbirths at or after 24 weeks of gestation, 4 neonatal deaths within 28 days after birth, and 990 live births of infants who survived to discharge from the hospital.

Preterm preeclampsia occurred in 26 of 1006 participants in the aspirin group, as compared with 70 of 990 in the placebo group (adjusted odds ratio in the aspirin group, $0.38 ; 95 \%$ confidence interval, 0.20 to $0.74 ; P=0.003)$. The size of the treatment effect was consistent across estimated risk groups at the time of screening, across groups defined according to obstetrical history, and across countries of the participating centers. The treatment effect for secondary outcomes, quantified as the odds ratio in the aspirin group with a $99 \%$ confidence interval. There was no significant between-group difference in the incidence of any secondary outcomes, but the trial was not powered for these outcomes.

In the aspirin group, at least one serious adverse event occurred in 26 participants and at least one adverse event occurred in 290 participants; in the placebo group, at least one serious adverse event occurred in 52 participants and at least one adverse event occurred in 320 participants. There was no significant between-group difference in the incidence of these events.

Table-1: Distribution in the aspirin group.

\begin{tabular}{|l|l|l|}
\hline \multicolumn{1}{|c|}{ Variables } & Number & $\begin{array}{c}\text { Percentage } \\
(\%)\end{array}$ \\
\hline Miscarriages before 24 weeks & 22 & 2.06 \\
\hline Pregnancy terminations for fetal abnormalities & 4 & 0.37 \\
\hline $\begin{array}{l}\text { Severe fetal growth restriction and } \\
\text { preeclampsia }\end{array}$ & 2 & 0.18 \\
\hline Stillbirths & 28 & 2.63 \\
\hline Neonatal death & 2 & 0.18 \\
\hline Live birth & 1006 & 94.54 \\
\hline
\end{tabular}


Table-2: Distribution in the placebo group.

\begin{tabular}{|l|l|l|}
\hline \multicolumn{1}{|c|}{ Variables } & Number & $\begin{array}{c}\text { Percentage } \\
(\%)\end{array}$ \\
\hline Miscarriages before 24 weeks & 24 & 2.28 \\
\hline Pregnancy terminations for fetal abnormalities & 8 & 0.76 \\
\hline $\begin{array}{l}\text { Severe fetal growth restriction and } \\
\text { preeclampsia }\end{array}$ & 0 & 0 \\
\hline Stillbirths & 24 & 2.28 \\
\hline Neonatal death & 4 & 0.38 \\
\hline Live birth & 990 & 94.28 \\
\hline
\end{tabular}

\section{Discussion}

Low-dose aspirin as prevention of preeclampsia (PE) has been widely examined but an indication for prescription, timing of treatment initiation, and dosage vary widely between the different studies and guidelines. The most common reason to take aspirin has been a previous history of PE or any other high-risk factors according to maternal characteristics and medical history. Nevertheless, the detection rate for preeclampsia using historybased guidelines is at best $40 \%[8,9]$.

Although many hypotheses have been proposed, the etiology of PE remains unclear. PE is thought to be associated with deficient production of prostacyclin and increased production of thromboxane A2 (TXA2) by the placenta and platelets. These findings have led to the use of antiplatelet agents in the prevention or amelioration of PE in pregnancy. Aspirin is an antiplatelet agent that inhibits cyclooxygenase production to a much higher degree than TXA2. In PE, aspirin is thought to rectify the imbalance between cyclooxygenase and TXA2. [7]. Therefore, low-dose aspirin (LDA) administration has been tried in various trials to examine its effect in the primary and secondary prevention of PE $[10,11]$.

In this multicenter, randomized, placebo-controlled trial involving women with singleton pregnancies who were identified using first-trimester screening as being at high risk for preterm preeclampsia, the administration of aspirin at a dose of $150 \mathrm{mg}$ per day from 11 to 14 weeks of gestation until 36 weeks of gestation was associated with a significantly lower incidence of preterm preeclampsia than was placebo. There was no significant between-group difference in the incidence of other pregnancy complications or adverse fetal or neonatal outcomes. However, the trial was not adequately powered for the secondary outcomes.
The recommendation that participants take aspirin at night, rather than during the day, was based on the observation from a randomized trial that treatment at this time may be superior in reducing the rate of preeclampsia. The incidence of preterm preeclampsia in the placebo group was lower than what was anticipated $(4.3 \%$, vs. the expected value of $7.6 \%$ ), and this finding is likely to be the consequence of differences between the demographic characteristics of the screened population and those of the population that was used for the development of the algorithm.

Despite the gastrointestinal symptoms reported in $10 \%$ of patients taking aspirin, there is no increase in the risk of bleeding or placental abruption $[12,13]$. Likewise, the literature indicates no significant association between low-dose aspirin treatment and premature closure of the arterial canal or neonatal bleeding [14-16]. However, the power of these studies was not enough to show the potential side effects associated with the routine and extensive prescription. Apart from pregnancy, large studies were needed to show the risks, notably hemorrhagic, associated with low-dose aspirin.

\section{Conclusion}

Aspirin is considered safe and has tolerable side effects but given the lack of data regarding adherence and long-term morbidity, primary prevention with universal prescription is not recommended.

\section{What does the study add to the existing knowledge?}

This randomized trial showed that among women with singleton pregnancies who were identified using first-trimester screening as being at high risk for preterm preeclampsia, the administration of aspirin at a dose of $150 \mathrm{mg}$ per day from 11 to 14 weeks of gestation until 36 weeks of gestation resulted in a significantly lower incidence of preterm preeclampsia than that with placebo.

\section{Author's contribution}

Dr. Chetna R Vaghela: Concept, study design

Dr. Vipul Nanjibhai Sarvaiya: Statistical analysis, manuscript preparation 


\section{Reference}

01. Navaratnam K, Alfirevic A, Alfirevic Z. Low dose aspirin and pregnancy: how important is aspirin resistance?. Int J Obstet Gynaecol. 2016;123(9)1481-1487. doi: $10.1111 / 1471-0528.13914$ [Crossref]

02. Russo I, Penna C, Musso T, Popara J, Alloatti G, Cavalot $F$, et al. Diabetes and myocardial ischemia/reperfusion injury. Cardiovasc Diabetol. 2017;16;71.

doi: 10.1186/s12933-017-0550-6 [Crossref]

03. Atallah A, Lecarpentier E, Goffinet F, Doret-Dion M, Gaucherand $P$, Tsatsaris V. Aspirin for prevention of preeclampsia. Drugs. 2017;77(17)1819-1831.

doi: $\quad 10.1007 / s 40265-017-0823-0 \quad$ [Crossref]

04. Bij de Weg JM, Abheiden CN, de Boer MA, de Groot C, de Vries JI. Patients' perspective on aspirin during pregnancy- a survey. Hypertens Pregnancy. 2020;9(4)371-378.

doi: $10.1080 / 10641955.2020 .1777299$ [Crossref]

05. Brown MA, Lindheimer MD, de Swiet M, Assche $\mathrm{AV}$, Moutquin JM. The classification and diagnosis of the hypertensive disorders of pregnancy- statement from the International Society for the Study of Hypertens in Pregnancy. Hypertens Pregnancy. 2001;20(1)IX-XIV. doi: 10.1081/PRG-100104165 [Crossref]

06. Uzan J, Carbonnel M, Piconne O, Asmar R, Ayoubi JM. Preeclampsia- pathophysiology, diagnosis, and management. Vasc Health Risk Manag. 2011;7;467-474.

doi: 10.2147/VHRM.S20181 [Crossref]

07. Prual A, Bouvier-Colle M-H, Bernis Ld, Breart G. Severe maternal morbidity from direct obstetric causes in West Africa- incidence and case fatality rates. Bull World Health Organ. $2000 ; 78(5) 593-602$.

[Crossref]

08. Loussert L, Vidal F, Parant O, Hamdi SM, Vayssiere C, Guerby P. Aspirin for prevention of preeclampsia and fetal growth restriction. Prenat Diagn. 2020;40(5)519-527.

doi: $10.1002 / p d .5645$ [Crossref]
09. Wertaschnigg D, Reddy M, Mol BW, da Silva Costa F, Rolnik DL. Evidence-Based Prevention of Preeclampsia- Commonly Asked Questions in Clinical Practice. J Pregnancy. 2019.

doi: $10.1155 / 2019 / 2675101$ [Crossref]

10. Warner TD, Nylander S, Whatling C. Anti-platelet therapy- cyclo oxygenase inhibition and the use of aspirin with particular regard to dual antiplatelet therapy. Brit J Clin Pharmacol. $2011 ; 72(4) 619-633$.

doi: $10.1111 /$ j.1365-2125.2011.03943.x [Crossref]

11. Zacharias-Millward N, Menter DG, Davis JS, Lichtenberger $L$, Hawke $D$, Hawk $E$, et al. Beyond COX-1- the effects of aspirin on platelet biology and potential mechanisms of chemoprevention. Cancer Metastasis Rev. 2017;36(2)289-303.

doi: $\quad 10.1007 / \mathrm{s} 10555-017-9675-z \quad$ [Crossref]

12. Bujold E, Roberge S, Lacasse $Y$, Bureau $M$, Audibert $F$, Marcoux $S$, et al. Prevention of preeclampsia and intrauterine growth restriction with aspirin started in early pregnancy- a metaanalysis. Obstet Gynecol. 2010;116(2 pt 1)402414.

doi: 10.1097/AOG.0b013e3181e9322a [Crossref]

13. Rotchell YE, Cruickshank JK, Gay MP, Griffiths J, Stewart A, Farrell B, et al. Barbados Low Dose Aspirin Study in Pregnancy (BLASP)- a randomised trial for the prevention of preeclampsia and its complications. $\mathrm{Br} \mathrm{J}$ Obstet Gynaecol. 1998;105(3)286-292.

doi: 10.1111/j.1471-0528.1998.tb10088.x [Crossref]

14. Di Sessa TG, Moretti ML, Khoury A, Pulliam DA, Arheart $\mathrm{KL}$, Sibai BM. Cardiac function in fetuses and newborns exposed to low-dose aspirin during pregnancy. Am J Obstet Gynecol. 1994;171(4)892-900.

doi: $10.1016 /$ S0002-9378(94)70056-7 [Crossref]

15. Schiessl B, Schneider KT, Zimmermann A, Kainer $F$, Friese $K$, Oberhoffer R. Prenatal constriction of the fetal ductus arteriosusrelated to maternal pain medication?. Geburtshilfe Neonatol. 2005;209(02)65-68.

doi: $10.1055 / \mathrm{s}-2005-864116$ [Crossref] 
16. Wyatt-Ashmead J. Antenatal closure of the ductus arteriosus and hydrops fetalis. Pediatr Dev Pathol Off J Soc Pediatr Pathol Paediatr Pathol Soc. $2011 ; 14(6) 469-474$.

doi: 10.2350/07-11-0368.1 [Crossref] 